\title{
UTILIZAÇÃO DE CANA-DE-AÇÚCAR HIDROLISADA COMO PRINCIPAL FONTE DE VOLUMOSO NA ALIMENTAÇÃO DE VACAS MESTIÇAS GIR X HOLANDES ${ }^{1}$
}

\author{
ALVES, Ana Carolina do Nascimento ${ }^{2}$ \\ EZEQUIEL, Jane Maria Bertocco ${ }^{3}$ \\ LIMA, Maria Lucia Pereira ${ }^{4}$
}

Recebido em: 2009-09-24

Aprovado em: 2009-10-21

ISSUE DOI: $10.3738 / 1982.2278 .309$

\begin{abstract}
RESUMO: A cana-de-açúcar possui valor nutritivo praticamente constante por período de tempo relativamente prolongado, garantindo índice de produção satisfatório, sendo um excelente recurso forrageiro. Porem deve-se considerar seu elevado conteúdo de parede celular, elevado teor de fibra em detergente ácido e reduzidos conteúdos de proteína bruta, levando a baixa digestibilidade da matéria seca, resultando em baixos níveis de consumo voluntário. Nesse contexto, o sistema de hidrólise alcalina utilizando-se hidróxido de cálcio tem apresentado boa eficiência técnica sobre melhoras na digestibilidade, porem a utilização de cal tem levando questões a respeito de elevados teores de cálcio na dieta de vacas em lactação, o que poderia ocasionar doenças metabólicas e perdas em produtividade. Este trabalho teve por objetivo estudar o efeito da hidrolise da cana-de-açúcar com hidróxido de cálcio em dietas para vacas em lactação, sobre parâmetros fisiológicos e metabólicos de níveis de cálcio, fósforo, magnésio no sangue e fezes. O trabalho foi conduzido no Instituto de Zootecnia - Agencia Paulista de Tecnologia dos Agronegócios, em Ribeirão Preto, utilizando-se 24 vacas da raça mestiças Gir X Holandês, com produção de leite ao redor de $17 \mathrm{~kg} \mathrm{~d}^{-1}$. As dietas foram formuladas através do programa NRC (2001). O período experimental teve duração de 84 dias, compostos de quatro sub-períodos de 28 dias, sendo os 21 primeiros dias para adaptação dos animais às dietas e os últimos 4 para coleta de dados segundo recomendações de Pimentel Gomes (1990). Os animais foram distribuídos em um delineamento inteiramente casualizado, composto por quatro tratamentos e seis repetições, totalizando 24 unidades experimentais.
\end{abstract}

Palavras-chave: Cálcio. Cana-de-açúcar. Fósforo. Hidrólise. Magnésio. Fecal. Perfil sérico.

SUMMARY: The sugar cane is a rich food in energy, presents high productivity, is available in the dry season and after the maturation keeps its nutritional value practically similar. However, sugar cane presents low digestibility of fiber that can decrease the dry matter intake. The alkaline treatment in the sugar-cane with $\mathrm{Ca}(\mathrm{OH}) 2$ can increase the fiber digestibility. The experiment was conducted using 24 dairy cows, with production of milk about of $17 \mathrm{~kg} . \mathrm{d}-1$ and corporal weight $500 \mathrm{~kg}$. The treatment was constituted of four experimental rations: a ration base contends cottonseed, urea, minerals, sunflower seed and sugar-cane in nature and another contends the same ingredients but using hydrolyzed sugar-cane at $1 \%$ as sugar-cane in nature and sunflower meal and sunflower oil. Were collected feces samples with intervals of two hours, representative of a collection day to verify the levels of $\mathrm{Ca}, \mathrm{P}$ and $\mathrm{Mg}$ of cows feces. Just de Ca presents significant difference. Three collected of blood was made in mammary vein, with intervals of two hours before the meal, soon after the meal and four hours after the meal to verify the levels of $\mathrm{Ca}, \mathrm{P}$ and $\mathrm{Mg}$ of cows blood feds with diets with high concentrations of $\mathrm{Ca}$. The results were $(\mathrm{mg} / \mathrm{dl})$ 8.19, 7.96 and 6.64 for $\mathrm{Ca}, 7.475 ; 6.38$ and 6.72 for $\mathrm{P}$ and 2.13; 1.88 and 2.23 for $\mathrm{Mg}$, for samples made two hours before the meal, soon after the meal and four hours after the meal. Just de Mg presents significant difference.

Keywords: Calcium. Hydrolysis. Magnesium. Phosphorus. Serum profile. Sugar cane.

\footnotetext{
${ }^{1}$ Parte da tese de doutorado da primeira autora, financiada pela Fapesp.

${ }^{2}$ Doutoranda em Zootecnia - UNESP/Jaboticabal. Bolsista CNPq e-mail: carualves@gmail.com

${ }^{3}$ Professora do Departamento de Zootecnia - FCAV - UNESP/Jaboticabal.

${ }^{4}$ Pesquisadora Cientifico Apta Regional, Ribeirão Preto-SP
} 


\section{INTRODUÇÃO}

A cana-de-açúcar tem sido amplamente utilizada para alimentação de bovinos por ter principalmente duas características: alta produção por área, o que propicia baixo custo por tonelada produzida, podendo ser consumida pelos animais justamente na época seca do ano, quando há falta de forragens para pastoreio. Outra vantagem de se utilizar a cana-de-açúcar como recurso forrageiro constitui-se no fato de seu valor nutritivo manter-se praticamente constante por um período de tempo relativamente prolongado, sendo os melhores valores obtidos com intervalos de cortes de 12 a 18 meses, contrastando com outras gramíneas tropicais (SANTOS, 2007)

O Brasil é hoje o maior produtor de cana-de-açúcar (Saccharum officinarum L). A produção mundial é de 1,6 bilhões de toneladas, sendo o Brasil é responsável por cerca de 514 milhões de toneladas (AGRIANUAL, 2009). Estima-se que 10\% da produção sejam destinados à alimentação animal, o suficiente para alimentar 15 milhões de bovinos durante 150 dias no ano (LANDELL et al., 2002)

No entanto, trabalhos de pesquisa mostraram que existem limitações em termos de consumo desta forrageira devido ao fato da baixa digestibilidade da FDN, limitando o consumo devido o enchimento ruminal (OLIVEIRA et al., 2001). Portanto, para melhorar as vantagens da utilização da cana-de-açúcar como principal suplemento volumoso na alimentação do gado leiteiro, é necessário o desenvolvimento de métodos de tratamento que promovam o rompimento da estrutura da fração fibrosa, para torná-la mais digestível.

Hidrólise é uma reação de ruptura de ligações químicas, promovidas pela água, em meio ácido ou alcalino, ou ainda, pelo calor, com despressurização brusca de material úmido hidrolisável. Os agentes alcalinizantes são utilizados para melhorar os coeficientes de digestibilidade da cana-de-açúcar e de outras forrageiras. Esses agentes atuam solubilizando parcialmente a hemicelulose, promovendo o fenômeno conhecido como entumescimento alcalino da celulose, que consiste na expansão das moléculas de celulose, causando a ruptura das ligações das pontes de hidrogênio, aumentando a digestão desta e da hemicelulose (OLIVEIRA et al., 2006).

$\mathrm{O}$ tratamento da cana-de-açúcar com $\mathrm{Ca}(\mathrm{OH})_{2}$ proporciona melhoria na digestibilidade, incremento na ingestão voluntária, aumento no consumo de água devido ao fato da lignina ser susceptível ao ataque hidrolítico, nas ligações covalentes do tipo éster entre a lignina e a parede celular (VAN SOEST, 1994). 
Os agentes alcalinizantes como o hidróxido de sódio $(\mathrm{NaOH})=$ soda; hidróxido de cálcio $\left(\mathrm{Ca}(\mathrm{OH})_{2}\right)=$ cal hidratada micropulverizada = hidróxido de cálcio (mín. 95,50); óxido de cálcio total (mín. 72,50); óxido de magnésio (máx. 1,50); amônia anidra $(\mathrm{NH} 3)$ e mais recentemente o óxido de cálcio $(\mathrm{CaO})=$ cal virgem micropulverizada, são utilizados para melhorar os coeficientes de digestibilidade dos volumosos (CAMPOS e BRUNO, 2008).

Segundo Ezequiel et al, (2002) o tratamento alcalino na cana-de-açúcar influencia positivamente a digestibilidade das frações fibrosas, proporcionando melhor aproveitamento da fibra da dieta, disponibilizando mais energia para estímulo do crescimento microbiano, elevando o aporte de proteína para os intestinos e digestibilidade mais elevada em relação à cana-de-açúcar in natura.

A maioria dos autores são unânimes em relatar que a cana-de-açúcar tratada com cal hidratada aumenta o aproveitamento de FDN, FDA, hemicelulose e a digestibilidade da MS melhorando sua estabilidade e composição química, porem segundo Silva et al (2006), o tratamento com cal hidratada aumenta os teores de MM e Ca e apesar do afinado controle homeostatico do organismo em relação ao calcio, existe relação entre o calcio e outros elementos minerais, capazes de interferir na biodisponibilidade desse mesmo mineral e de outros. Nesse contexto, a excreção de cálcio, fósforo e magnésio e suas interrelações no metabolismo absortivo, têm sido muito estudadas, sendo grande o interesse em conhecer a interdependência desses íons e a influência que eles exercem entre si, especialmente quando existe alteração de um deles.

\section{MATERIAL E MÉTODOS}

O trabalho foi conduzido no confinamento do Instituto de Zootecnia - Agencia Paulista de Tecnologia dos Agronegócios, em Ribeirão Preto, utilizando-se 24 vacas da raça mestiças Gir X Holandês, com produção de leite ao redor de $17 \mathrm{~kg} \mathrm{~d}-1$, peso vivo de $500 \mathrm{~kg}$ e consumo de $16 \mathrm{~kg} / \mathrm{MS}$. A dieta foi formulada através do programa NRC (2001). O período experimental teve duração de 84 dias, compostos de quatro subperíodos de 28 dias, sendo os 24 primeiros dias para adaptação dos animais às dietas e os últimos 4 para coleta de dados segundo recomendações de Pimentel Gomes (1990). Os animais foram distribuídos em um delineamento inteiramente casualizado. Os tratamentos foram constituídos de quatro rações experimentais: uma ração base contendo milho, farelo de algodão, mineral, semente de girassol e cana-de-açúcar in 
natura (Cana In Natura e Semente de Girassol); uma ração controle contendo os mesmos ingredientes supracitados porem substituindo a cana in natura por cana hidrolisada a 1\% (Cana Hidrolisada e Semente Girassol); uma ração contendo cana hidrolisada e farelo de girassol (Cana Hidrolisada e Farelo de Girassol) e outra contendo cana hidrolisada e óleo de girassol (Cana Hidrolisada e Óleo de Girassol). Foi utilizada para hidrolisar a cana-de-açúcar a cal hidratada calcítica especial com composição química de: Oxido de cálcio total $(\mathrm{CaO})$ mínimo de $72 \%$; Óxido de magnésio total $(\mathrm{MgO})$ máximo de $2 \%$; Hidróxido de Cálcio $(\mathrm{Ca}(\mathrm{OH}) 2)$ mínimo de $95 \%$; umidade máxima de $1 \%$ conforme análise fornecida pelo fabricante. A hidrólise foi feita a $1 \%$ por meio de máquina e kit hidrocana, utilizando água como veiculo para pulverização. A cana foi pulverizada de forma homogenia, amontoada e coberta com lona plástica para ser oferecida aos animais 24 horas após a hidrólise. A dieta contendo cana-deaçúcar in natura apresentou 4,7g de $\mathrm{Ca}, 3,2 \mathrm{~g}$ de $\mathrm{P}$ e 2,8g de $\mathrm{Mg}$ por $\mathrm{kg}$ de $\mathrm{MS}$ e as dietas contendo cana-de-açúcar hidrolisada apresentaram $12 \mathrm{~g}$; 9,9g e 7,8g de Ca por $\mathrm{kg}$ de MS; 2,4g; 3,1g e 2,9g de P por $\mathrm{kg}$ de MS e 2,8g; $3 \mathrm{~g}$ e 2,7g de $\mathrm{Mg}$ por $\mathrm{kg}$ de MS respectivamente. A dieta apresentou 9,9g de Ca por kg de MS; 4,1g de P por kg/MS e 3,5 g de Mg por $\mathrm{kg} / \mathrm{MS}$, ou seja, os animais ingeriram cerca de 153,5g de Ca por dia (exigência de $55,1 \mathrm{~kg} \mathrm{~d}^{-}{ }^{1}$ ), 63,60g de $\mathrm{P}$ e $54,28 \mathrm{~g}$ de $\mathrm{Mg}$ por dia. Foram colhidas três amostras de sangue pela veia mamária e acopladas em tubos contendo gel separador, com intervalos de duas horas antes da refeição (jejum), logo após a refeição (pósprandial) e quatro horas após a refeição. Os tubos contendo as amostras foram imediatamente centrifugados após a colheita a 4000xg por 20 minutos, obtendo-se alíquotas de 1,5 mL de soro. As concentrações séricas de magnésio e cálcio foram determinadas pelo método enzimático-colorimétrico utilizando kits comerciais e determinação de fósforo sérico por colorimetria, também utilizando kits comerciais, segundo as normas da AOAC (1996). Foram colhidas também amostras de fezes, com intervalos de duas em duas horas representativas de um dia de coleta total e foi realizada digestão nítrico-perclórica e posterior diluição para determinação das leituras para cálcio e magnésio que foram realizadas em espectrofotômetro de absorção atômica e de fósforo por colorimetria, segundo as normas da AOAC (1996). 


\section{RESULTADOS E DISCUSSÃO}

Para os níveis séricos de Ca, pode-se observar queda sem diferença significativa no intervalo pós-prandial e quatro horas após a alimentação, conforme resultados apresentados na Tabela 1.

TABELA 1: Médias de Ca, $\mathrm{P}$ e Mg séricos nos diferentes tempos de coleta, jejum, pós prandial e quatro horas após a alimentação (md/dL)

\begin{tabular}{llll}
\hline & Jejum & Pós-prandial & Quatro horas após \\
\hline $\mathrm{Ca}$ & $8,19 \mathrm{a}$ & $7,96 \mathrm{a}$ & $6,64 \mathrm{a}$ \\
\hline$P$ & $7,475 \mathrm{a}$ & $6,38 \mathrm{a}$ & $6,72 \mathrm{a}$ \\
\hline $\mathrm{Mg}$ & $2,13 \mathrm{a}$ & $1,88 \mathrm{~b}$ & $2,23 \mathrm{a}$
\end{tabular}

Letras minúsculas iguais nas linhas não diferem significativamente pelo teste de Tukey $(\mathrm{P}>0,05)$.

Esse resultado pode ser explicado pelo fato da absorção intestinal de Ca ser dividida em duas partes: uma ativa saturável, a qual é mediada pela vitamina $\mathrm{D}$ e envolve a proteína ligadora de $\mathrm{Ca}(\mathrm{Ca}-\mathrm{Bp})$ e uma passiva, que pode corresponder a difusão simples ou facilitada. Sendo assim, o aumento do Ca dietético foi seguido de um aumento proporcional na quantidade do elemento absorvido por difusão, enquanto que a absorção ativa foi saturada. Assim, a fração dietética de Ca que seria absorvida no intervalo quatro horas após a alimentação, diminuiu com o aumento da chegada do mesmo no intestino. Para o mineral $\mathrm{P}$ também não foi observado diferença significativa entre os intervalos de coletas, porem os níveis séricos também diminuíram no pós-prandial e quatro horas após a refeição, tal resultado pode ser explicado devido cerca de $70 \%$ do $\mathrm{P}$ ingerido ser absorvido a nível intestinal (jejuno preferencialmente) e sua absorção depender da vitamina $\mathrm{D}$, do $\mathrm{pH}$ intestinal e do Ca que em excesso na dieta desestimula o PTH, levando também a perda na absorção de P conforme demonstrou Anderson, 2003. No que se refere a absorção de $\mathrm{Mg}$, sua absorção ocorre de 30 a $50 \%$ na ingestão oral, na porção jejunoileal do intestino delgado. Os elevados teores de $\mathrm{Ca}$ e P, influenciaram na absorção de $\mathrm{Mg}$ devido a competição pela vitamina $\mathrm{D}$, fazendo com que o mesmo se apresente menor significativamente no período pós-prandial; e por ser reabsorvido de forma ativa no néfron e passiva no túbulo proximal os rins conservaram o magnésio sérico de forma eficiente, em particular quando sua ingestão foi baixa em relação aos 
outros macrominerais, explicando o fato do mesmo estar novamente aumentado no intervalo quatro horas após a alimentação.

Para os teores de Ca nas fezes, pode-se observar aumento significativo para os tratamentos que receberam cana-de-açúcar hidrolisada Tabela 2.

TABELA 2: Teores de $\mathrm{Ca}, \mathrm{P}$ e $\mathrm{Mg}$ nas fezes nos diferentes tratamentos (g/kg/MS)

\begin{tabular}{|c|c|c|c|c|}
\hline & Cana & & Cana & Cana \\
\hline & In Natura e & Cana & Hidrolisada & Hidrolisada \\
\hline & Semente de & Hidrolisada e Semente & e Farelo de & e Óleo de \\
\hline & Girassol & Girassol & Girassol & Girassol \\
\hline $\mathrm{Ca}$ & $9,03 \mathrm{~b}$ & $20,4 \mathrm{a}$ & $21,9 \mathrm{a}$ & 19,9 a \\
\hline$P$ & $6,51 \mathrm{a}$ & $6,15 \mathrm{a}$ & $6,60 \mathrm{a}$ & $6,65 \mathrm{a}$ \\
\hline$M g$ & $4,54 \mathrm{a}$ & $4,56 \mathrm{a}$ & $4,43 \mathrm{a}$ & $4,53 \mathrm{a}$ \\
\hline
\end{tabular}

Os resultados ocorreram devido à quantidade de cálcio absorvido ser determinada pela ingestão e pela capacidade de absorção intestinal. Sendo assim, se a ingestão é baixa, a absorção é alta, enquanto que na ingestão alta a absorção é menor. Assim, pode-se explicar que após a ingestão de minerais como o $\mathrm{P}$ e o $\mathrm{Ca}$, uma porção pode permanecer sem ser absorvida, podendo, portanto, ser recuperada nos excrementos. O mesmo ocorre com a absorção de magnésio, que também é função direta dos níveis dietéticos assim, as fezes podem conter quantidades de nutrientes que tenham sido absorvidos, metabolizados ou que foram logo eliminados, via intestino conforme os resultados apresentados no presente estudo e conforme afirma Andriguetto et al, (2002).

\section{CONCLUSÕES}

Em vacas mestiças alimentadas com dietas a base de cana-de-açúcar hidrolisada como principal fonte de volumoso, existe relação entre o excesso de $\mathrm{Ca}$ na dieta e a absorção de $\mathrm{Ca}, \mathrm{P}$ e $\mathrm{Mg}$, e após a ingestão em excesso desses minerais, uma porção pode permanecer sem ser absorvida, podendo, portanto, ser recuperada nos excrementos 
podendo ocasionar o aumento da contaminação ambiental, porem ainda é necessário avaliar, se esse excesso pode ocasionar distúrbios metabólicos e queda na produção leiteira.

\section{REFERÊNCIAS}

AGRIANUAL 2009: Anuário da Agricultura Brasileira. São Paulo: FNP Consultoria e Comércio, 2009. 497p.

ANDERSON J.J.B. Nutrição para a saúde óssea. In: Mahan LK, Escott-Stump S (eds). Krause - Alimentos, nutrição e dietoterapia. 10a .ed. São Paulo: Editora Roca, 2003. pp. 591-611.

ANDRIGUETTO, J. M. Nutrição Animal, as bases e os fundamentos da nutrição animal. Os alimentos. São Paulo: Nobel, 2002. V.1

ASSOCIATION OF OFFICIAL ANALYTICAL CHEMISTS INTERNATIONAL. Official methods of analysis. Vol 1. 15th ed. AOAC, Alington, V. A. 1996

CAMPOS, F.S, BRUNO L. Sitio Eletrônico. Disponível em: http://www.ufv.br/pdpl/jornal/jpl0805_f.htm Acesso em 08/novembro/2008

EZEQUIEL, J., M., B; MELÍCIO, S., P., L; SANCANARI, J., B., D; FERREIRA, R., N; FEITOSA, J., V; Quantificação das Bactérias Sólido-Aderidas, Bactérias e Protozoários Líquido-Associados do Rúmen de Bovinos Jovens Alimentados com Amiréia. Revista Brasileira de Zootecnia, v.31, n.2, p.707-715, 2002

LANDELL, M. G.; CAMPANA, M. P.; RODRIGUES, A. A., A variedade IAC 862480 como nova opção de cana-de-açúcar para fins forrageiros: manejo de produção e uso na alimentação. Série tecnologia APTA, Boletim Técnico IAC 193, 2002, 36p.

NRC. Nutrient Requeriments of Dairy Cattle. 6th revised Edition. National Resserch Council. Natl. Acad. Sci. Washington, D. C. 2001

OLIVEIRA, A. S. Produção de proteína microbiana e estimativas das excreções de derivados de purinas e de uréia em vacas lactantes alimentadas com rações isoprotéicas contendo diferentes níveis de compostos nitrogenados não-protéicos. Revista Brasileira de Zootecnia, Viçosa, v. 30, n. 5, p. 1621-1629, 2001.

OLIVEIRA; M. D. S. D., SHINODA; J., BODRICK; R., SANTOS; J. D., LOPES; A. D., SILVA; T. M., OLIVEIRA; I. S., MOTA; D. A., BRITO; A. R. B. Efeito da hidrolise com a cal hidróxido de cálcio sobre a composição bromatologica da cana-deaçúcar (saccharum officinarum 1.) REUNIÃO ANUAL DA SOCIEDADE BRASILEIRA DE ZOOTECNIA.43 João Pessoa, 2006: Anais... João Pessoa: SBZ, CD-ROM, 2006 
PIMENTEL GOMES, F. 1990. Curso de Estatística Experimental. 13a.ed. Nobel, Piracicaba, SP, Brasil.

SANTOS, M. C. Aditivos químicos para o tratamento de cana-de-açúcar in natura e ensilada (Saccharum offcinarum L.) 113f. Dissertação (mestrado) Esalq, Piracicaba, 2007.

SILVA; R. A. D., CACERE; E. R., DIAS; A. C. D. S., RIBEIRO; C. B., SOUZA; A. R. D. L., VASCONCELOS; P. C., MORAIS; M. D. G., FRANCO; G. L. Efeito da adição de cal hidratada na cana-de-açúcar picada sobre a composição química e digestibilidade in vitro da matéria seca. REUNIÃO ANUAL DA SOCIEDADE BRASILEIRA DE ZOOTECNIA.43 João Pessoa, 2006: Anais... João Pessoa: SBZ, CD-ROM, 2006

VAN SOEST, P. J. Nutritional ecology of the ruminant. 2.ed. Ithaca: Cornell University Press, 1994. 476 p. 